\title{
Dislocation Density and Texture in Copper Deformed by Cold Rolling and Ecap
}

\author{
Talita Gama de Sousa ${ }^{a}$, Vitor Luiz Sordi ${ }^{b}$ Luiz Paulo Brandão ${ }^{a *}$ \\ ${ }^{a}$ Seção de Engenharia de Materiais, Instituto Militar de Engenharia, Praça General Tibúrcio 80, 22290- \\ 270, Praia Vermelha, Rio de Janeiro, RJ, Brazil \\ ${ }^{b}$ Departamento de Engenharia dos Materiais, Universidade Federal de São Carlos, Rodovia \\ Washington Luís, km 235, 13565-905, São Carlos, SP, Brazil
}

Received: May 23, 2017; Revised: August 24, 2017; Accepted: September 17, 2017

\begin{abstract}
Analysis of dislocation density in metallic materials has been pursued with great interest for many years because dislocations are closely associated with plastic deformation and thus exert a deep effect on the mechanical properties of any material. Crystallographic texture has also a decisive influence in some properties. In this work, the dislocation density was estimated from the line broadening of X-ray diffractograms using the Convolutional Multiple Whole Profile Program (CMWP) and crystallographic texture analyses were performed using inverse pole figures (IPF). The material used in this research was pure copper deformed by cold rolling and Equal Channel Angular Pressing (ECAP). The dislocation density values obtained by Transmission Electron Microscopy (TEM) and X-ray Diffraction (XRD) were compared and discussed. While, in the case of cold rolling, the crystallographic texture of the material was enhanced with increasing deformation, it was reduced with increasing deformation in the case of ECAP processing.
\end{abstract}

Keywords: dislocation density, copper, cold rolling, ECAP, crystallographic texture

\section{Introduction}

Among the quantities used to describe plastic deformation, two of the most important for the understanding of the mechanical behavior of metallic materials during deformation are the dislocations density and the crystallographic texture.

When a metal is plastically deformed, the bulk of the energy involved in the process is dissipated as heat, but some energy is stored, increasing the internal energy. This stored energy is associated with an increase in the amount of crystal defects, such as dislocations. During the deformation process, multiple dislocations, which interact among themselves and with other microstructural features, promote the formation of complex cellular substructures ${ }^{1,2}$.

Dislocation density is a microstructural feature that can be investigated by several techniques, but the most commonly used are $\mathrm{TEM}^{3}$ and $\mathrm{XRD}^{4}$. Through TEM, the dislocation density can be obtained by quantitative stereology relations, such as the one proposed by Ham in 1961. In this method, a set of random lines with a total length $L$ is projected in a given area $A$ of a TEM micrograph and the number of intersections $N$ that dislocations make with the grid lines is used to estimate the dislocation density using the equation ${ }^{3}$

$$
\rho=2 N / L t
$$

where $\rho$ is the dislocation density and $t$ is the sample thickness.
In the case of XRD, the dislocation density is estimated from the broadening of the diffraction peaks using an appropriate function to model the shape of the diffraction line. Over the years, methods and programs have been developed to estimate the dislocation density from diffraction line profiles. In particular, a group of researchers from the Institute of Physics of the Eötvös Loránd University in Hungary developed a computer program called Convolutional Multiple Whole Profile (CMWP) that evaluates several microstructural parameters of the diffraction profiles, among them the value of $\rho^{5}$.

The CMWP program is based on concepts similar to those of the Rietveld refinement. In other words, it involves generating a theoretical diffraction pattern represented by analytic functions and fitting this pattern to the experimental diffractogram. The theoretical diffraction pattern is represented by ${ }^{5}$ :

$$
I_{\text {theoretical }}=B G(2 \theta)+\sum_{h k l} I_{M A X}^{h k l} I^{h k l}\left(2 \theta-2 \theta_{0}^{h k l}\right)
$$

where $B G(2 \theta)$ is the background function, $I_{M A X}^{h k l}$ is the peak intensity, $2 \theta_{0}^{h k l}$ is the $2 \theta$ value at the peak and $I_{M A X}^{h k l}$ is the theoretical profile function (peak broadening) for the $h k l$ reflection.

The theoretical profile function is expressed by a Fourier transform obtained by convolution of the measured instrumental profile function, the crystallite size profile function, the microstrain profile function for dislocations and the profile function of the stacking faults. The instrumental profile function is obtained from a standard sample, which necessarily provides a large number of well separated 
reflections in the entire angular range, a minimum of strain and a large grain size.

The theoretical microstrain profile function is a function of $\rho$ and is given by ${ }^{5}$ :

$$
A^{D}(L)=\exp \left[-\frac{\pi b^{2}}{2}\left(g^{2} C\right) \rho L^{2} f\left(\frac{L}{R e}\right)\right]
$$

where $f$ is the strain function, $g$ is the absolute value of the diffraction vector, $L$ is the displacement of the atoms relative to their ideal position, $b$ is the absolute value of the Burgers-vector and $R e$ is a length parameter. The $\mathrm{C}$ parameter is the contrast factor of the dislocation, which depends on the elastic constants of the material, the orientation, the diffraction vector, the Burgers vector, the line vector and the normal vector of the slip plane of the dislocation ${ }^{6}$.

The crystallographic texture assessment may also be done using the XRD technique. For this, three different pole figures are measured and the orientation distribution function (ODF) is calculated via spherical harmonics. Then, the inverse pole figures (IPF) are recalculated and plotted.

In this work, the dislocation density of the copper deformed by cold rolling and ECAP was studied by the XRD and TEM. The results obtained using the two methods were compared and found to be consistent. The Vickers hardness of the materials was measured and related to the dislocation density. The crystallographic texture was significantly dependent on the deformation process and led to strengthening of the samples deformed by cold rolling and weakening of the samples deformed by ECAP.

\section{Material and Methods}

The material used in this study was copper (99.9\%) supplied by Paranapanema Company as sheets ( $3.17 \mathrm{~mm}$ thick) for cold rolling and as a round bar $(9.52 \mathrm{~mm}$ in diameter) for ECAP. The sheets and the bar were annealed at $600{ }^{\circ} \mathrm{C}$ for $1 \mathrm{~h}$, cooled to room temperature in the furnace and then pickled by immersion in a $10 \% \mathrm{H}_{2} \mathrm{SO}_{4}$ solution for $10 \mathrm{~min}^{7}$. Samples taken from the sheets and the bar at this stage and named CA, they were also called as underformed materials.

The sheets were cold rolled with reduction of $10 \%, 30 \%$, $50 \%, 70 \%$ and $85 \%$ in thickness and named C10, C30, C50, $\mathrm{C} 70$ and $\mathrm{C} 85$, respectively.

Billets of $10 \mathrm{~mm}$ diameter and $70 \mathrm{~mm}$ length were cut from the bar and processed using 1 to 4 ECAP passes at room temperature, following route $\mathrm{B}_{\mathrm{c}}$, in a die with an angle between the channels of $\Phi=120^{\circ}$ and an outer angle of curvature of $\Psi=22^{\circ}$. The samples were extruded with $\mathrm{MoS}_{2}$ base lubrication and named C1X, C2X, C3X and C4X for 1, 2, 3 or 4 passes, respectively.

In order to compare the samples deformed by rolling and by ECAP, the equivalent strain for both deformation routes was calculated. The equivalent true strain for the rolling process is given by ${ }^{8}$

$$
\bar{\varepsilon}=\frac{2 \sqrt{3}}{3} \varepsilon_{3}
$$

where $\varepsilon_{3}$ is the true thickness strain.

The equivalent strain calculated for ECAP processing, is given by ${ }^{9}$

$$
\bar{\varepsilon}=\frac{N}{\sqrt{3}}\left(2 \cot \left(\frac{\Phi}{2}+\frac{\Psi}{2}\right)+\Psi \operatorname{cosec}\left(\frac{\Phi}{2}+\frac{\Psi}{2}\right)\right)
$$

where $N$ is the number of passes, $\Phi$ is the channel intersection angle and $\Psi$ is the outer angle or curvature.

The samples to be analyzed by XRD were ground, mechanically polished with diamond paste and chemically polished with a solution containing 1 part of $\mathrm{HNO}_{3}, 1 \frac{1}{4}$ parts of acetic acid $\left(\mathrm{CH}_{3} \mathrm{CO}_{2} \mathrm{H}\right)$ and $23 / 4$ part of phosphoric acid $\mathrm{H}_{3} \mathrm{PO}_{4}{ }^{7}$.

The X-Ray diffractograms were recorded using a PANalytical X'Pert PRO MRD diffractometer with Co$\mathrm{K} \alpha$ radiation. The XRD patterns were analyzed through the HightScore Plus software. A standard sample of $\mathrm{LaB}_{6}$ powder was used for measuring the instrumental profile (Figure 1). The dislocation density was estimated using the CMWP program and the contrast factors were calculated and measured using the ANIZC program ${ }^{10}$. The CMWP program was developed by Gábor Ribárik and Tamás Ungar, both belonging to the Institute of Physics of the Eötvös Loránd University located in Hungary. The program is available by access web browsers through the website http://www.renyi. $\mathrm{hu} / \mathrm{cmwp}$. The ANIZC program was used through the site http://metal.elte.hu/anizc.

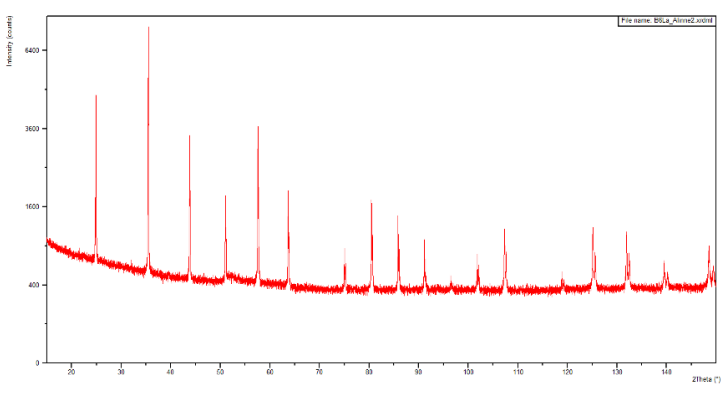

Figure 1. Diffractogram of the LaB6 standard.

The sample used to demonstrate the procedure performed by the CMWP program was the $30 \%$ rolled copper, C30. The first step was to obtain the sample diffractogram as shown in Figure 2. For the refinement of the diffraction peaks line broadening, the instrumental profile and crystallite size effect were taken in account by the software. The program provides the refinement graph of the sample as a result, allowing its users to evaluate the adjustment quality. Figure 3 shows the refinement graph of the C30 sample. The same procedure was used for the other samples.

The crystallographic texture was investigated via inverse pole figures calculated by the popLA code using (111), (200) 


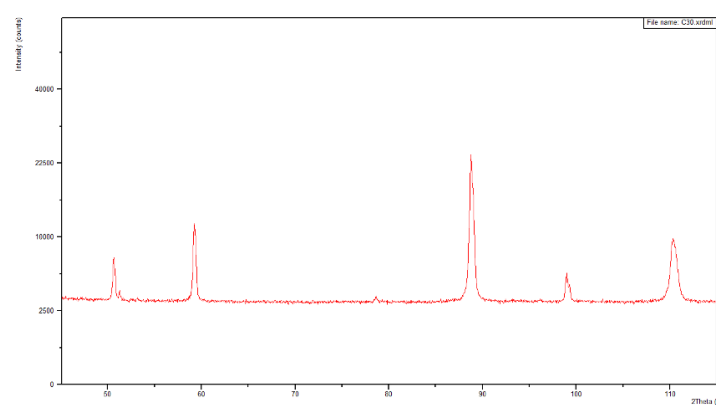

Figure 2. Diffractogram of the $\mathrm{C} 30$ sample.

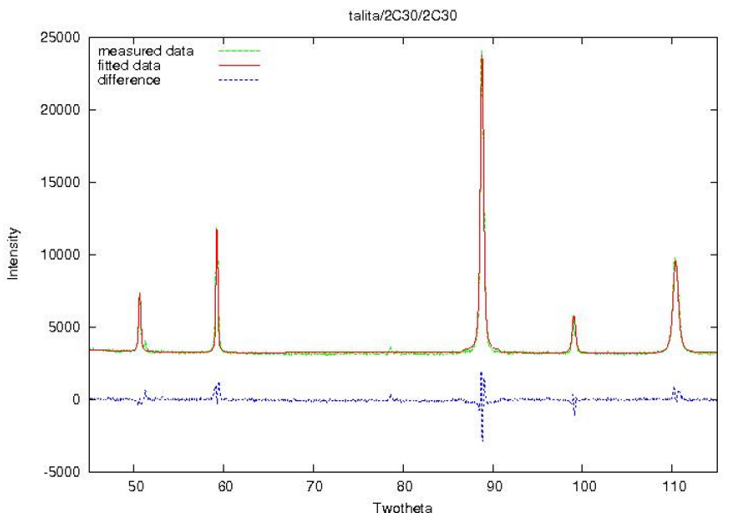

Figure 3. Diffractogram of the $\mathrm{C} 30$ sample after refinement with its difference line.

and (220) pole figures measured by XRD. For cold rolled samples, the rolling direction was taken as reference direction; for the samples deformed by ECAP, the radial direction was taken as reference direction. In order to compare the two results, the texture was analyzed using the (001) inverse pole figures for the rolled samples and the (100) IPF for the samples deformed by ECAP.

The TEM micrographs were recorded using a JEOL JEM-2100F Transmission Electron Microscope. The samples were prepared by electrolytic polishing in a $30 \%\left(\mathrm{HNO}_{3}\right)$ and $70 \%$ methanol $\left(\mathrm{CH}_{3} \mathrm{OH}\right)$ solution at room temperature. The dislocation density was determined using the Ham intercept $\operatorname{method}^{3}$. Four micrographs were obtained in two different grains for CA samples and three micrographs were obtained per region in four different grains for $\mathrm{C} 85$ samples $^{11,12}$. The sample thickness values needed to calculate the dislocation density were obtained by the Electron Energy Loss Spectroscopy (EELS) technique.

The Vickers hardness tests were performed on all samples and the final result was the average of six indenting marks per specimen. The areas used for the test were ground and mechanically polished with diamond paste. The Vickers penetration test was performed using loads of $10 \mathrm{~g}(98.07 \mathrm{mN})$.

\section{Results and Discussion}

A graph of the dislocation density versus equivalent strain for samples deformed by cold rolling and by ECAP. It is shown in Figure 4.

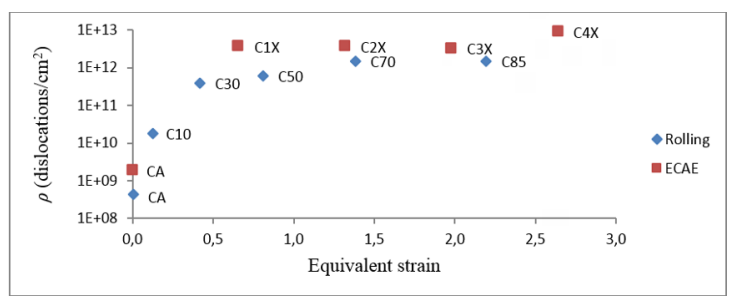

Figure 4. Dislocation density $\rho$ versus equivalent strain

For cold rolled samples, the dislocation density increases with deformation. As can be seen in Figure 4, $\rho$ is about $10^{8}$ dislocations $/ \mathrm{cm}^{2}$ for undeformed samples, $10^{11}$ dislocations/ $\mathrm{cm}^{2}$ for specimen with $30 \%$ reduction and $10^{12}$ dislocations/ $\mathrm{cm}^{2}$ for $70 \%$ reduction. The increase in dislocation density was expected and can be explained by the generation and multiplication of dislocations that occur during the deformation of cold worked metals. On the other hand, the dislocation density changed very little in the final stages of deformation, i.e., from $70 \%$ to $85 \%$. This saturation was also expected, since it is known that the dislocation sources are not infinitely activated during deformation due to stacking of dislocations in the slip plane. There is also a competition between generation and annihilation of dislocations due to a dynamic recovery process that probably starts to operate at high deformation levels. Similar results were also reported by Haberjahn et al. ${ }^{13}$.

In the case of samples deformed by ECAP, the effect of the first pass is much larger than that of the subsequent passes, making the dislocation density increase from about $10^{9}$ dislocations $/ \mathrm{cm}^{2}$ for undeformed samples to $10^{12}$ dislocations $/ \mathrm{cm}^{2}$. This behavior also observed by Murata et al. ${ }^{14}$ and Mishra et al. ${ }^{15}$ and attributed to a dynamic balance between the generation and annihilation of dislocations after the first pass.

It should be noted that although the dislocation density saturates in both processes, saturation occurs for lower values of equivalent strain in the case of samples deformed by ECAP.

On can also see in Figure 4 that, for similar levels of equivalent strain, the dislocation density of samples deformed by ECAP is larger than that of samples deformed by cold rolling, which suggest that ECAP processing is more effective than cold rolling in accumulating dislocations. This difference could be due to several factors. First, the deformation mechanisms are different in the two processes: cold rolling involves plane strain, while ECAP it is almost pure shear. Moreover, it is known that there are differences in the strain rate and, consequently, in the strain hardening imposed to the material by the two processes, which are also reflected on the dislocation density. Other aspects that should be also considered are related to the microstructure. In particular, there is a correlation between the strain state and microstructure. For example, Miyajima et al ${ }^{16}$ observed that the dislocation density depends on grain shape and size in the case of samples deformed by ECAP. Ungar et al. ${ }^{17}, \mathrm{Ni}$ et al. ${ }^{18}$ and Dalla Torre et al. ${ }^{19}$ showed that, for similar values of equivalent strain, the grain sizes in samples deformed by 
ECAP are smaller than in samples deformed by cold rolling. Other factor that should be taken into account is the number of subgrain boundaries. Cobos-Higuera et al. ${ }^{20}$ showed that subgrain boundaries are more numerous in samples deformed by ECAP than in samples deformed by cold rolling.

Figure 5 shows a graph of hardness versus equivalent strain for samples deformed by cold rolling and by ECAP. It can be seen that, for the same equivalent deformation, the hardness of the samples deformed by cold rolling is always smaller than the sample deformed via ECAP. The reasons for this behavior are probably similar of those presented in the discussion of the paragraph before this where it was discussed the relation between dislocation density and deformation process to the same equivalent deformation. One should bear in mind that the amount of equivalent strain is higher in one pass of ECAP than in one pass of rolling. ECAP samples hardness increased abruptly after the first pass and remains almost constant up to the third pass. After the fourth ECAP pass, the samples showed an increase in hardness but no appreciable increase in the dislocation density. According to Habibi et al. ${ }^{21}$ this late increase in hardness can be attributed to subgrain structural changes during the last ECAP pass.

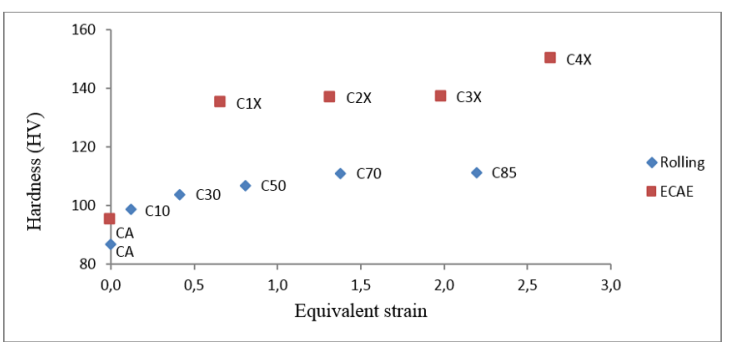

Figure 5. Hardness versus equivalent strain

Another goal of this work was to compare the values of the dislocation density measured by XRD and TEM. For this, we used an undeformed sample and a cold rolled sample with $85 \%$ reduction (C85). Figure 6 and Figure 7 show typical micrographs of CA and C85 samples, respectively.

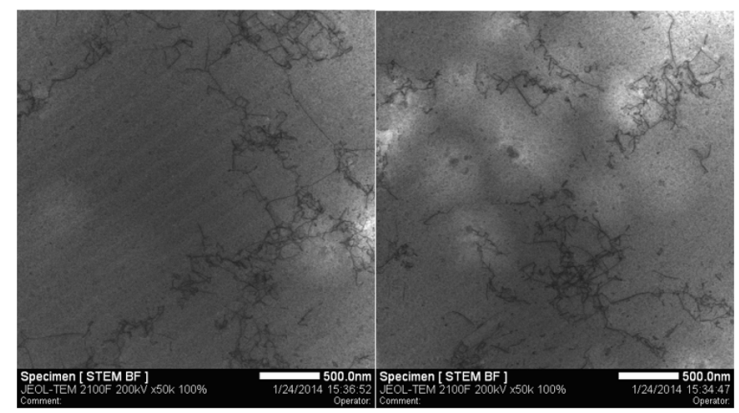

Figure 6. Micrographs of sample CA.

The dislocation densities estimated from TEM micrographs, using Eq. (1), and from XRD results, are shown in Table 1. The results are consistent in the sense that both yield smaller

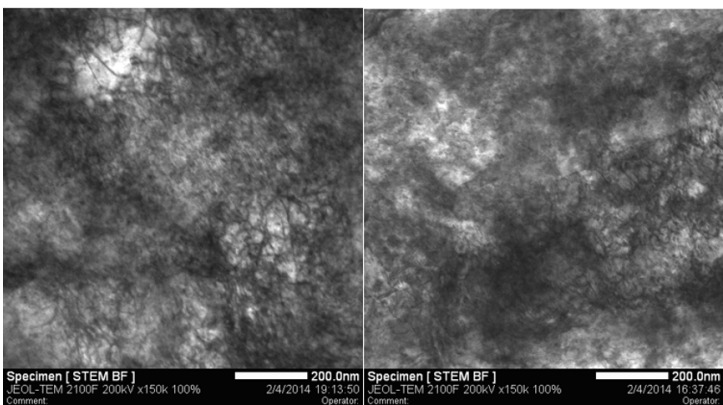

Figure 7. Micrograph of sample C85.

values of the dislocation density for the undeformed sample than for the cold rolled sample. However, a discrepancy was observed with respect to the values of dislocation density. In the case of the underformed sample, the TEM results yielded a larger value for the dislocation density than the XRD results, while the opposite happened in the case of the deformed sample. For the underformed sample, an overestimate of the value obtained by TEM can be attributed to a systematic error in the selection of the investigated area, as suggested by Sousa et al. ${ }^{22}$. For the deformed sample, a possible source of error in the TEM measurements is the great difficulty in counting individual dislocations in the dense dislocation tangles of highly deformed samples (Figure 7), favoring an underestimate of the dislocation density, as previously reported by Sousa et al. ${ }^{22}$ and Bailey and Hirsch ${ }^{12}$. Thus, despite the differences, values found by XRD and TEM can be considered appropriate and self-consistent ${ }^{23}$. While the TEM results were presumably impacted by systematic errors, which can be reduced increasing the number analyzed areas ${ }^{11}$, the XDR technique provided reliable and more practical results, in agreement with the findings of Ribárik et al. ${ }^{24}$.

Table 1. Dislocation density measured by TEM and XRD.

\begin{tabular}{ccc}
\hline \multirow{2}{*}{ Sample } & \multicolumn{2}{c}{$\rho\left(\right.$ dislocations $\left./ \mathrm{cm}^{2}\right)$} \\
\cline { 2 - 3 } & TEM & XRD \\
\hline CA & $7.76 \pm 2.46 \times 10^{9}$ & $4.57 \times 10^{8}$ \\
C85 & $1.42 \pm 0.15 \times 10^{11}$ & $1.43 \times 10^{12}$ \\
\hline
\end{tabular}

Figure 8 shows the inverse pole figures (IPF) of samples C50, C70 and C85, deformed by cold rolling. The IPF of samples $\mathrm{C} 1 \mathrm{X}, \mathrm{C} 2 \mathrm{X}$ and $\mathrm{C} 3 \mathrm{X}$, deformed by ECAP, is shown in Figure 9.

According to Figure 8, in samples deformed by cold rolling, the texture intensity increases with deformation. On the other hand, as can be seen in Figure 9, in samples deformed by ECAP, the texture intensity decreases with the number of passes; after the third pass, the texture has almost disappeared. This decrease is due to the fact that the direction and/or sense of shear strain imposed by the process is different in each pass, leading to a dispersion of the texture. It is also important to remark that the texture of the $\mathrm{C} 1 \mathrm{X}$ sample is already relatively low. 


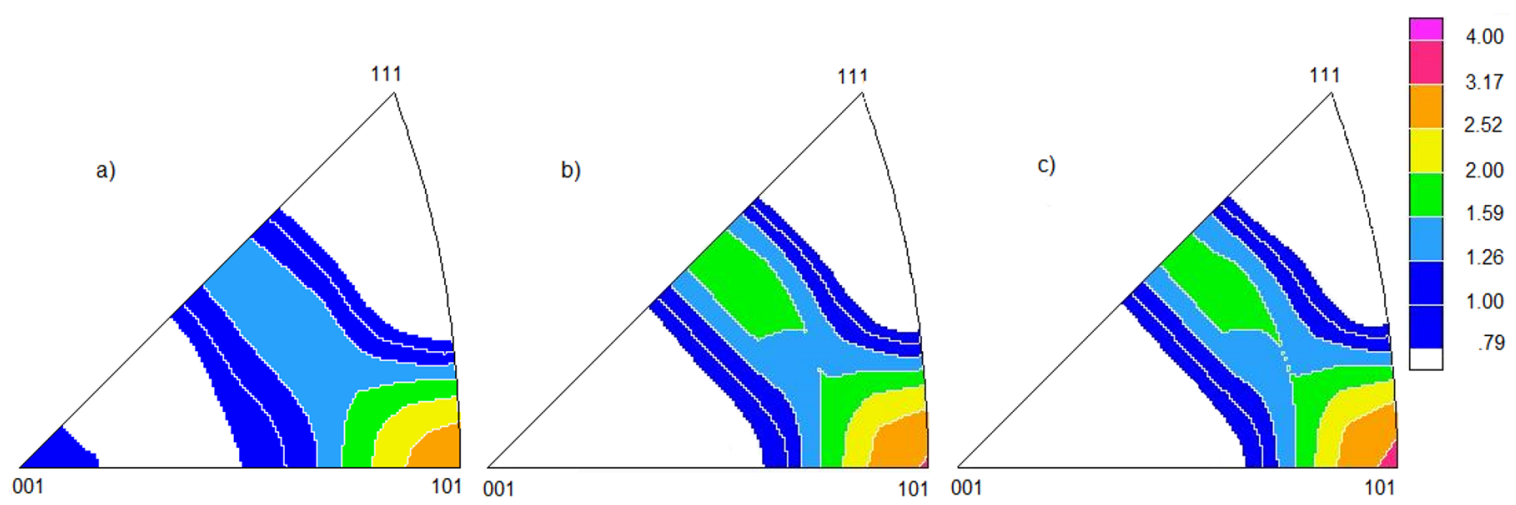

Figure 8. Inverse (001) pole figures of cold rolled copper samples with a reduction of a) $50 \%$, b) $70 \%$ and c) $85 \%$.
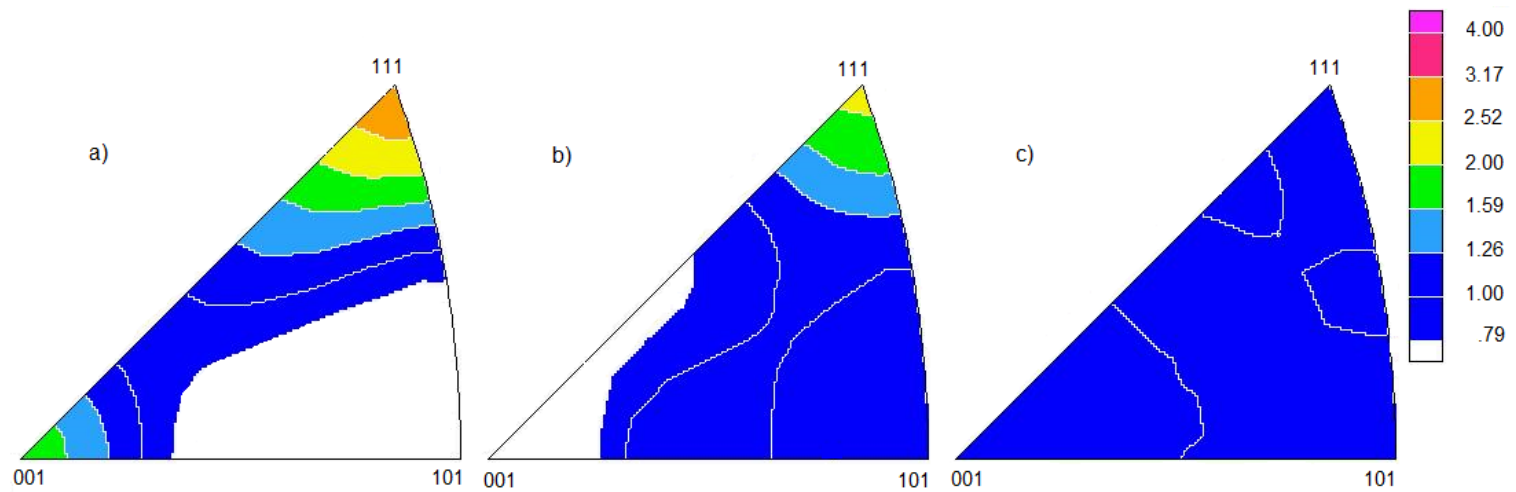

Figure 9. Inverse (100) pole figures of deformed copper samples by ECAP using route Bc after a) 1, b) 2 and c) 3 passes.

Also, one can check a texture change due to the type of route used. Observing the IPF's of ECAP samples, it is evident that after odd passes there is the presence of the (001) pole while after the even passes it disappears. It is possible to realize that for the odd passes the shear direction are the same but in the opposite sense, what may explain the decrease in the (001) pole intensity after the second odd pass when compare to the first. The shear planes in pass 2 are in different direction and sense when compared to the odd passes, what may explain the absence of the (001) pole in its IPF. Furukama et al. ${ }^{25}$ and Kliauga et al ${ }^{26}$ have already related the effect of this shear plane crossing on the material texture using different ECAP routes, including the $\mathrm{Bc}$ route. Kliauga et al. ${ }^{26}$ also reported that using $\mathrm{Bc}$ route, the sample texture tends to become more random after some ECAP passes. El-Dana $\mathrm{f}^{27}$ has also reported that commercially pure aluminum texture starts to become smoother after the ECAP fourth step, when the $\mathrm{Bc}$ route was used.

Oppositely to ECAP, cold rolling IPF's conducted to a continuous enhancing of the texture intensity with passes. Unlikely the ECAP process, the rolling always occurs in the same direction favoring the intensification of some texture components. This fact can be perceived through the intensity of the (101) and (112) poles after each pass.

\section{Conclusions}

From the results obtained in this work, it can be concluded that, for copper,

- The evolution of dislocation density in samples deformed by rolling and ECAP is consistent with the progress of the deformation processes;

- The measurements of dislocation density by XRD and hardness are consistent fir both deformation processes;

- Measurement of dislocation density by XRD line broadening is qualitatively consistent with TEM results;

- In samples deformed by cold rolling, the texture intensity increases with deformation; while, in samples deformed by ECAP, the texture intensity decreases with the number of passes and almost disappears after three passes.

\section{Acknowledgments}

The authors would like to thank CAPES for financial support and Instituto Militar de Engenharia (IME) and Universidade Federal de São Carlos (UFSCar) for the use of laboratory facilities. The authors also would like to thank 
Centro Brasileiro de Pesquisas Físicas (CBPF), especially Dr. André Luiz Pinto, for support in the TEM analysis.

\section{References}

1. Barker I, Hansen N, Ralph B. The development of deformation substructures in face-centred cubic metals. Materials Science and Engineering: A. 1989;113:449-454.

2. Hughes DA, Hansen N. High angle boundaries formed by grain subdivision mechanisms. Acta Materialia. 1997;45(9):38713886 .

3. Ham RK. The Determination of dislocation densities in thin films. Philosophical Magazine. 1961;6(69):1183-1184.

4. Langford JI, Louer D. Powder diffraction. Reports on Progress in Physics. 1996;59(2):131-234.

5. Ribárik G. Modeling of diffraction patterns based on microstructural properties. [Thesis]. Budapest: Eötvös Loránd University; 2008.

6. Ungár T, Dragomir I, Révész A, Borbély A. The contrast factors of dislocations in cubic crystals: the dislocation model of strain anisotropy in practice. Journal of Applied Crystallography. 1999;32(Pt 5):992-1002.

7. Van der Voort GF. Metallography: Principles and Practice. $2^{\text {nd }}$ ed. New York: McGraw-Hill; 1984.

8. Backofen WA. Deformation Processing. Boston: AddisonWesley; 1972.

9. Iwahashi Y, Wang J, Horita Z, Nemoto M, Langdon TG. Principles of equal-channel angular pressing for the processing of ultra-fine grained materials. Scripta Materialia. 1996;35(12):143-146.

10. Borbély A, Dragomir-Cernatescu J, Ribárik G, Ungár T. Computer program $A N I Z C$. for the calculation of diffraction contrast factors of dislocations in elastically anisotropic cubic, hexagonal and trigonal crystals. Journal of Applied Crystallography. 2003;36(Pt 1):160-162.

11. Hirsch PB, Howie A, Nicholson RB, Pashley DW, Whelan MJ. Application of the dynamical theory to crystals containing dislocations. In: Hirsch PB, ed. Electron Microscopy of Thin Crystals. London: Butterworths, 1965. p. 247-275.

12. Bailey JE, Hirsch PB. The dislocation distribution, flow stress, and stored energy in cold-worked polycrystalline silver. Philosophical Magazine. 1960;5(53):485-497.

13. Haberjahn M, Klimanek P, Motylenko M. Substructure development in cold rolled copper single crystals. Materials Science and Engineering: A. 2002;324(1-2):196-199.

14. Murata Y, Nakaya I, Morinaga M. Assessment of Strain Energy by Measuring Dislocation Density in Copper and Aluminium Prepared by ECAP and ARB. Materials Transactions. 2008;49(1):20-23.
15. Mishra A, Kad BK, Gregori F, Meyers MA. Microstructural evolution in copper subjected to severe plastic deformation: Experiments and analysis. Acta Materialia. 2007;55(1):13-28.

16. Miyajima Y, Okubo S, Abe H, Okumura H, Fujii T, Onaka S, et al. Dislocation density of pure copper processed by accumulative roll bonding and equal-channel angular pressing. Materials Characterization. 2015;104:101-106.

17. Ungár T, Gubicza J, Hanák P, Alexandrov I. Densities and character of dislocations and size-distribution of subgrains in deformed metals by X-ray diffraction profile analysis. Materials Science and Engineering. 2001;319-321:274-278.

18. Ni H, Zhang XY. Quantitative defect evolution of nanocrystalline nickel during cold rolling. Philosophical Magazine Letters. 2012;92(4):202-210.

19. Dalla Torre F, Lapovok R, Sandlin J, Thomson PF, Davies CHJ, Pereloma EV. Microstructures and properties of copper processed by equal channel angular extrusion for 1-16 passes. Acta Materialia. 2004;52(16):4819-4832.

20. Higuera-Cobos OF, Cabrera JM. Mechanical, microstructural and electrical evolution of commercially pure copper processed by equal channel angular extrusion. Materials Science and Engineering: A. 2013;571:103-114.

21. Habibi A, Ketabchi M, Eskandarzadeh M. Nano-grained pure copper with high-strength and high-conductivity produced by equal channel angular rolling process. Journal of Materials Processing Technology. 2011;211(6):1085-1090.

22. Sousa TG, Diniz SB, Pinto AL, Brandão LP. Dislocation Density by X-ray diffraction in $\alpha$ Brass Deformed by Rolling and ECAE. Materials Research. 2015;18(Suppl 2):246-249.

23. Grabova RB, Gorbatov VK, Ostrovsky ZE, Yuskaev RA. Microstructural study of an irradiated high-nickel alloy by X-ray line profile analysis and TEM observations. Journal of Nuclear Materials. 1997;240(3):229-235.

24. Ribárik G, Ungár T. Characterization of the microstructure in random and textured polycrystals and single crystals by diffraction line profile analysis. Materials Science and Engineering: $A$. 2010;528(1):112-121.

25. Furukama M, Iwahashi Y, Horita Z, Nemoto M, Langdon TG. The shearing characteristics associated with equal-channel angular pressing. Materials Science and Engineering: A. 1998;257(2):328-332.

26. Kliauga AM, Bolmaro RE, Ferrante M. The evolution of texture in an equal channel pressed aluminum AA1050. Materials Science and Engineering: A. 2015;623:22-31.

27. El-Danaf EA. Texture evolution and fraction of favorably oriented fibers in commercially pure aluminum processed to 16 ECAP passes. Materials Science and Engineering: A. 2008;492(1-2):141-152. 